\title{
A Learning Design Framework to Support Children with Learning Disabilities Incorporating Gamification Techniques
}

\author{
Adel Shaban \\ Teesside University \\ England, UK \\ A.shaban@tees.ac.uk
}

\author{
Elaine Pearson \\ Teesside University \\ England, UK \\ E.pearson@tees.ac.uk
}

\section{ABSTRACT}

Gamification is increasingly being applied in education to engage and motivate learners. Yet the application of gaming elements can be problematic because it can have a negative effect on cognitive load $(C L)$ and on working memory (WM). This is a particular issue for children with learning disabilities who suffer from deficits in working memory. While studies have explored the relationship between gamification and cognitive load, there is little research to address the management of cognitive load in gamified learning applications for children with learning disabilities. This study is suggesting a framework based on existing guidelines derived from $\mathrm{HCl}$ concepts and cognitive load theories to design user-centered gamified applications for children with learning disabilities to exploit their limited WM capacity and manage cognitive load.

Permission to make digital or hard copies of part or all of this work for personal or classroom use is granted without fee provided that copies are not made or distributed for profit or commercial advantage and that copies bear this notice and the full citation on the first page. Copyrights for third-party components of this work must be honored. For all other uses, contact the Owner/Author.

CHI'19 Extended Abstracts, May 4-9, 2019, Glasgow, Scotland UK

() 2019 Copyright is held by the owner/author(s).

ACM ISBN 978-1-4503-5971-9/19/05.

https://doi.org/10.1145/3290607.3312806 


\section{KEYWORDS}

Gamification Framework; Gamification Techniques; Design Guidelines; HCl; UserCentered; Cognitive Load; Learning Disabilities; Working Memory.

\section{INTRODUCTION}

Gamification is an interesting and exciting research topic in $\mathrm{HCl}$ [18]. $\mathrm{HCl}$ research aims at designing better online game interfaces for improving interaction and user satisfaction [10]. Thus, good gamified design should enhance user experience and engagement, provide fun, and delight [13]. Several studies have suggested that different individuals respond differently to gamified applications[18]. Thus, helping specific users to find meaningful connections with the underlying non-game activities is the main aim of gamification which could improve the end-user experience and help designers to opt for the most appropriate game mechanics based on needs, preferences, and characteristics of the end-users[14]. Conversely, the inclusion of difficult and distracting game elements may have a negative influence on users' performance by inducing unneeded stress or new cognitive demands[11], [19]. In addition to that, the competition with other participants to reach resources and internal or external incentives results in negative emotional responses such as anxiety that may affect stress levels and result in distraction from the main purpose[9]. There is a known high positive correlation between competition anxiety and cognitive load [3], [9]; thus, game designers should consider cutting (diminishing) the competition anxiety and cognitive load by enlarging (extending) the competitive time [9], and applying cognitive load management principles[19].

Gamification has a negative impact on cognitive load, academic performance and learning motivation; although it can have a positive impact on learning anxiety [17]. Therefore, competition with other users or competitive elements should be considered in favour of effectiveness in terms of anxiety and exploiting the limited working memory capacity of the participants for learning or training instead of overloading it. Avoiding complex activities was suggested to manage cognitive load in gamification [19], especially for individuals who suffer from limited working memory (WM) capacity. WM is the ability of the brain to hold and manipulate information for very brief periods of time [1]. WM has a limited capacity, and its exact size varies from one person to another [20]. Studies have shown that individuals with learning difficulties (LD) suffer from WM deficits (e.g. [15], [12]). Therefore, appropriate design strategies should be implemented to minimize the load on the users' WM [20].

Brunken et al. [4] indicated that the core instructional design issue is not only to reduce the amount of cognitive load in WM (diminish overload) per se, but also to find the appropriate level of cognitive load for each learner. Also, instructional designs should be developed to help learners to use their memory capacities effectively[20]. Therefore, guidelines to design meaningful gamification for children with learning disabilities based on the concepts of human-centered design and cognitive load theories could exploit their limited WM capacity, manage cognitive load in designing gamified applications, improve their experience, and motivate them.

Gamification and its design methods has attracted some criticism [6]. For example, it is not 


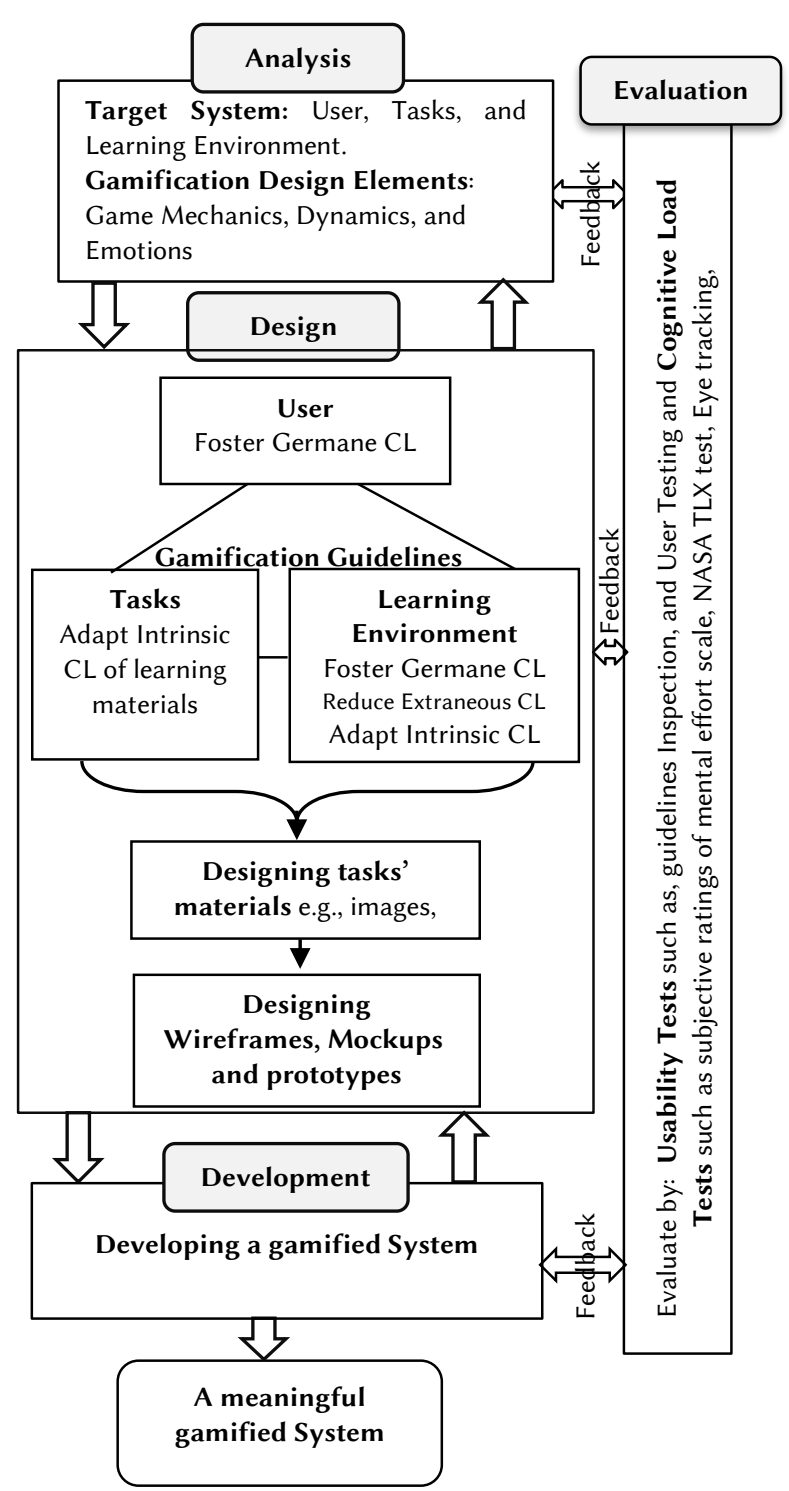

Figure 1: The Proposed Framework systematic, is reward-oriented and pattern-bound, and is not user-centric. Furthermore, it is not automatically obvious what gamification design elements exemplify. Researchers depict them by examples, such as "points, leaderboards, level \& status, quests \& challenges, progression and virtual badges" [10]; others have suggested taxonomies or frameworks. MDA framework (mechanics, dynamics, and aesthetics) and its adaptable version MDE (mechanics, dynamics, and emotions) are the common frameworks in gamification. Ruhi, [16] presented an adapted MDA framework to clear up the connections between end-user motivations and interactive gamification elements on one side, and technology features and functions on the other side that constitute effective gamification interventions, in addition to suggesting a set of guidelines to manage and design gamified initiatives and applications. This framework for design and research, aims to create meaningful engagement for end-users. A set of design principles using the proposed framework was proposed. However, there appears to be no frameworks or design guidelines to develop meaningful gamified applications for children with learning disabilities.

This paper aims to bridge this gap in research by proposing a framework incorporating a set of guidelines based on the concepts of $\mathrm{HCl}$ (e.g. usability, user-centered design, and user experience) and cognitive load theories principles to develop meaningful gamified applications specific to children with LD.

\section{THE PROPOSED FRAMEWORK}

The framework presented in Fig. 1, is a systematic model, aiming to develop meaningful and enjoyable gamified applications for children with learning disabilities. It consists of four components; analysis, design, development, and evaluation. The framework is illustrated by reference to a prototype application for children with learning disabilities.

\section{Analysis}

Analyse target system. This stage, involves identifying user characteristics, expectations, needs, prior knowledge, experience etc. Children with LD, the intended users in this study, can be defined as children having normal intelligence not matched with their low learning potential or scholastic achievement [5]. Moreover, those children have poor WM capacity and poor reading and/or writing capability, and often fail to complete common schoolroom activities especially those requiring recall of information. They also have difficulty in following directions and multi-step instructions, distinguishing between/among letters, numbers, or sounds and generating new solutions problems. They may also have short attention spans and high levels of distractibility [2, 7]. Based on the characteristics of children with LD, their prior knowledge, expectations and needs, the instructional materials and tasks or activities (nature of tasks, goals, learning outcomes, level of difficulty, familiarity, and interactivity of elements, etc.) can be identified. In addition, the most appropriate technology and learning environment (web, desktop, interface, etc.) is selected. Gamification design elements. Selecting the gamification elements for children with LD is 
Table 1: Proposed User Guidelines

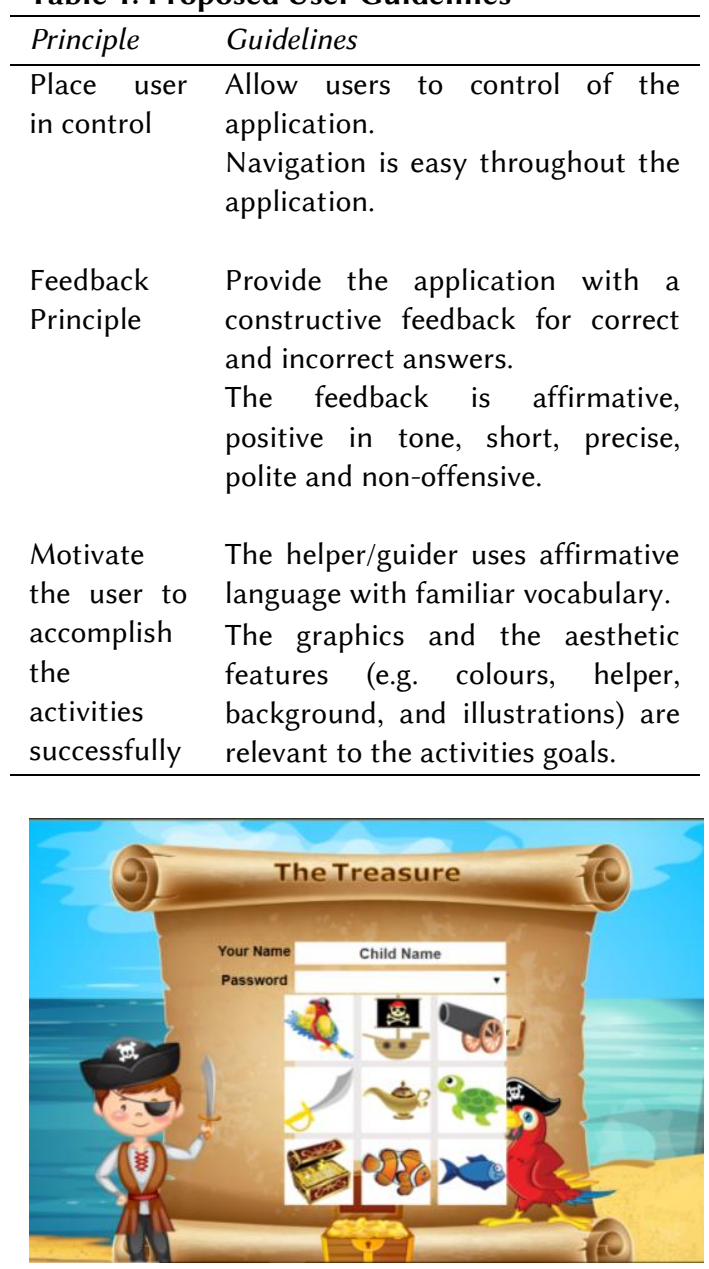

Figure 2: Visual Password example for children with LD dependent on the target system information. Exploiting the WM capacity of children with LD in choosing game mechanics, dynamics, and emotions could aid in managing cognitive overload in gamified systems through presenting the content in a meaningful and enjoyable story to help children to discover connections between the application activities[14]. Short tasks (in duration) with points as rewards may keep children engaged and attentive [8]. Furthermore, a form of internal competition (virtual competitor) instead of external competition with other children, by excluding elements such as leader boards, may reduce the anxiety of competition with others, decrease cognitive load and promote intrinsic motivation [19]. Increasing the competitive time could cut the competition anxiety and cognitive load[9]. Occasional gamification rewards for achievements and regular practice keep children engaged and interested over time. The idea of "mandatory fun" can reduce intrinsic motivation; therefore, children should have the autonomy to choose to participate or not in gamified systems, badges and leader boards that makes a gamification system more effective[8]. Finally, adding difficult and distracting game elements may have an adverse effect on children's performance by inducing pointless stress or new cognitive demands[11, 19]. The analysis stage can be evaluated through the creation of UX personas.

\section{Design}

To design a user-centered gamified application for children with LD, a comprehensive review and evaluation of the research, theory and guidelines related to Cognitive Load Theory (CLT), multimedia learning design, gamification design frameworks, and $\mathrm{HCl}$ concepts (usability, usercentered design, and UX) has been carried out. This has resulted in a set of guidelines to get maximum usability and minimum cognitive overload through reducing extraneous, managing intrinsic, and increasing germane cognitive load. The guidelines cover the following three categories:

User guidelines. Aim to foster germane cognitive load; therefore, the application should be designed to allow the child to be in control of the application through navigation and support elements. In the prototype, progress in the application is self- paced, allowing the child to complete the training or activity at any time and at his or her own pace. To minimise text input and reading overload, a visual password consisting of nine images from which the user selects three images to form the password is provided as shown in Fig. 2. A narrate option makes all buttons, icons, and main elements readable with mouse hover to enhance accessibility. Constructive audio feedback is employed both for correct responses (e.g. "excellent", and "well done"), and for incorrect responses (e.g. "keep trying", and "you tried very hard"). Further support to accomplish the activities successfully are also incorporated (Table 1).

Learning materials guidelines. Aim to manage intrinsic cognitive load in learning activities through the modality principle, segmenting principle and coherence principle such as: Modality principle: the prototype takes the form of a visual, spoken, and exciting story. Segmenting principle: 
Table 2: Proposed Learning Materials Guidelines

\begin{tabular}{|c|c|}
\hline Principle & Guidelines \\
\hline $\begin{array}{l}\text { Modality } \\
\text { principle }\end{array}$ & $\begin{array}{l}\text { The application relies on spoken } \\
\text { and visual activities, rather than } \\
\text { written ones. } \\
\text { The activities content is attractive, } \\
\text { simple, and meaningful for users. }\end{array}$ \\
\hline $\begin{array}{l}\text { Pre- } \\
\text { training } \\
\text { and } \\
\text { guided } \\
\text { activity } \\
\text { principle }\end{array}$ & $\begin{array}{l}\text { Provide pre-training through an } \\
\text { animated helper at the beginning } \\
\text { of the application and every } \\
\text { activity as well. } \\
\text { Provide the user with the essential } \\
\text { information to carry out each } \\
\text { activity. } \\
\text { The pre-training uses a friendly } \\
\text { and positive tone. } \\
\text { The goals of the application } \\
\text { and each activity are clear. }\end{array}$ \\
\hline $\begin{array}{l}\text { Segmenti } \\
\text { ng } \\
\text { principle }\end{array}$ & $\begin{array}{l}\text { Present the activities as discrete } \\
\text { activities/games. } \\
\text { Present the activities in different } \\
\text { levels. }\end{array}$ \\
\hline $\begin{array}{l}\text { Signalling } \\
\text { principle }\end{array}$ & $\begin{array}{l}\text { Highlight the most important } \\
\text { elements. } \\
\text { Use verbal and pictorial cues } \\
\text { sparingly in activities. }\end{array}$ \\
\hline $\begin{array}{l}\text { Coherenc } \\
\text { e principle }\end{array}$ & $\begin{array}{l}\text { All activities are relevant to the } \\
\text { application goals. } \\
\text { Provide a concise report on the } \\
\text { user's achievement at the end of } \\
\text { each activity. }\end{array}$ \\
\hline
\end{tabular}

the prototype consists of short and discrete activities/games, each with a target, levels, and rewards. Familiarisation techniques of pre-training at the beginning of the application and an emulated example before every activity /game are also used. Coherence principle: each activity/game is followed by a concise report on the user's achievement, and a final report is given at the end of every session or set of activities to indicate the score. In addition, a virtual helper introduces the application and supports the child at any time in the application (Table 2).

Learning Environment guidelines. Aim to decrease extraneous cognitive load through well designed activities and interface layout, excluding non-essential material and making the application intuitive to use. Therefore, the principles of consistency, aesthetic and minimalist design; appropriate help and error messages are incorporated into the prototype (Table 3).

The prototype will be assessed by a set of expert reviewers by applying heuristics inspection. The improvements identified by those reviewers along with the feedback obtained while performing user testing with children will be incorporated into the final application.

\section{Development}

The final gamified application is now ready to be developed. On completion, a set of usability, user experience, and cognitive load tests will be performed. User testing through tasks, amended subjective ratings of mental effort to measure cognitive load level in activities and ensure that the intended application is easy to use, functional, and enjoyable for children with LD. In sum, the application will be tested to determine the extent to which it can support children with LD to achieve their needs and expectations.

\section{IMPLICATIONS FOR THE CHI COMMUNITY}

The expected contribution of $\mathrm{HCl}$ is a better understanding of how to design user-centered gamified applications for children with LD in the light of a new systematic framework and a set of guidelines derived from the concepts of $\mathrm{HCl}$ and cognitive load theories in addition to identifying the appropriate game elements and effective evaluation methods specific for those children.

\section{CONCLUSION}

A systematic framework and a set of guidelines are proposed to develop user-centered gamified applications for children with learning disabilities. The framework is grounded in instructional design models, $\mathrm{HCl}$ concepts (usability, user-centered design, and UX principles), working memory and cognitive load principles, and gamification design principles to overcome overload in gamification applications and exploit children's working memory capacity to focus on the task. This could motivate and encourage children to undertake the training required and to assimilate new schemas and knowledge. The next stage of this research is to design a full application by applying the revised framework and to evaluate the application with children through usability testing methods and cognitive load tests. 


\section{Table 3: Proposed Learning Environment}

\section{Guidelines}

Principle Guidelines

Consistenc Elements are consistent

y principle throughout the application.

Aesthetic Design application story and the and graphics to be attractive for the minimalist children

design The number of links and buttons on

principle each page is appropriate.

There are no distracting elements (e.g. movement, blinking, scrolling).

Choices are kept to a maximum of 3-

4 (drop-down menu items, recalled elements).

The contrast between text and background is sufficient.

Use clear and readable fonts for those children (e.g., Sans-serif fonts, Arial, Verdana).

The icons are simple, labeled, and familiar for users.

Help and Users can skip the instructions at the Error beginning of the application and Messages activities.

principle The application uses constructive error messages with polite, nonoffensive and plain-language.

Warn the user before exit of activities or application.

Users can use help (auditory/visual animated) at any time throughout the whole application.

\section{REFERENCES}

[1] Alloway, T.P., Gathercole, S.E., Kirkwood, H. and Elliott, J. 2008. Evaluating the validity of the Automated Working Memory Assessment. Educational Psychology. 28, 7 (Dec. 2008), 725-734.

[2] Alloway, T.P., Gathercole, S.E., Kirkwood, H. and Elliott, J. 2009. The cognitive and behavioral characteristics of children with low working memory. Child Development. 80, 2 (Apr. 2009), 606-621.

[3] Allsop, J., Gray, R., Bülthoff, H. and Chuang, L. 2016. Effects of anxiety and cognitive load on instrument scanning behavior in a flight simulation. (Oct. 2016), 55-59.

[4] Brünken, R., Plass, J.L. and Moreno, R. 2010. Current Issues and Open Questions in Cognitive Load Research. Cognitive Load Theory. J.L. Plass, R. Moreno, and R. Brünken, eds. 253-272.

[5] Chen, X., Ye, M., Chang, L., Chen, W. and Zhou, R. 2017. Effect of Working Memory Updating Training on Retrieving Symptoms of Children With Learning Disabilities. Journal of Learning Disabilities. (Jun. 2017), 0022219417712015. DOI:https://doi.org/10.1177/0022219417712015.

[6] Deterding, S. 2013. Skill atoms as design lenses for user-centered gameful design. Workshop Papers CHI2013 (2013).

[7] Gathercole, S. 2009. Identifying and supporting children with working memory problems memory problems. Workshop presentation, 12h Annual Residential SEN Conference 2009 Individual Needs

[8] Hanus, M.D. and Fox, J. 2015. Assessing the effects of gamification in the classroom: A longitudinal study on intrinsic motivation, social comparison, satisfaction, effort, and academic performance. Computers \& Education. 80, (Jan. 2015) 152-161. DOl:https://doi.org/10.1016/j.compedu.2014.08.019.

[9] Hwang, M.-Y., Hong, J.-C. Cheng, H.-Y., Peng, Y.-C. and Wu, N.-C. 2013. Gender differences in cognitive load and competition anxiety affect 6th grade students' attitude toward playing and intention to play at a sequential or synchronous game. Computers \& Education. 60, 1 (Jan. 2013), 254-263.

[10] Kankanhalli, A., Taher, M., Cavusoglu, H. and Kim, S.-H. 2012. Gamification: A New Paradigm for Online Use Engagement. ICIS (2012)

[11] Katz, B., Jaeggi, S., Buschkuehl, M., Stegman, A. and Shah, P. 2014. Differential effect of motivational features on training improvements in school-based cognitive training. Frontiers in Human Neuroscience. 8, (2014) DOI:https://doi.org/10.3389/fnhum.2014.00242.

[12] Maehler, C. and Schuchardt, K. 2016. Working memory in children with specific learning disorders and/or attention deficits. Learning and Individual Differences. 49, (Jul. 2016), 341-347.

[13] Marache-francisco, C. and Brangier, E. 2013. Process of Gamification From The Consideration of Gamification To Its Practical Implementation. CENTRIC 2013 (2013).

[14] Nicholson, S. 2013. Two Paths to Motivation through Game Design Elements: Reward-Based Gamification and Meaningful Gamification - Google Search. iConference 2013 Proceedings (2013), 671-672).

[15] Peng, P. and Fuchs, D. 2016. A Meta-Analysis of Working Memory Deficits in Children With Learning Difficulties: Is There a Difference Between Verbal Domain and Numerical Domain? Journal of Learning Disabilities. 49, 1 (Jan. 2016), 3-20. DOI:https://doi.org/10.1177/0022219414521667.

[16] Ruhi, U. 2016. Level Up Your Strategy: Towards a Descriptive Framework for Meaningful Enterprise Gamification. Technology Innovation Management Review 5, 8: 5-16. DOI:http://doi.org/10.22215/timreview/918.

[17] Su, C.-H. 2016. The effects of students' motivation, cognitive load and learning anxiety in gamification software engineering education: a structural equation modeling study. Multimedia Tools and Applications. 75, 16 (Aug. 2016), 10013-10036. DOI:https://doi.org/10.1007/s11042-015-2799-7.

[18] Tondello, G.F. 2016. An introduction to gamification in human-computer interaction. XRDS: Crossroads, The ACM Magazine for Students. 23, 1 (2016), 15-17.

[19] Turan, Z., Avinc, Z., Kara, K. and Goktas, Y. 2016. Gamification and Education: Achievements, Cognitive Loads, and Views of Students. International Journal of Emerging Technologies in Learning (iJET). 11, 07 (Jul. 2016), 64-69.

[20] Budiu, R. 2018. Working Memory and External Memory: 2018. https://www.nngroup.com/articles/working-memory external-memory/. Accessed: 2019-01-02. 